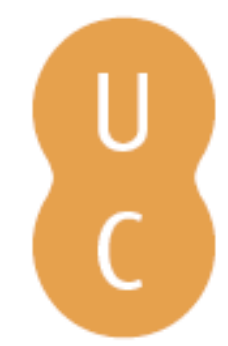

\title{
nombalina
}

\section{Poder e Território: o Alto Alentejo entre o Império e a Antiguidade Tardia}

\author{
Autor(es): $\quad$ Carneiro, André
}

Publicado por: Imprensa da Universidade de Coimbra

URL

persistente:

URI:http://hdl.handle.net/10316.2/34765

DOI:

DOI:http://dx.doi.org/10.14195/978-989-26-0626-2_15

Accessed : $\quad$ 26-Apr-2023 10:20:32

A navegação consulta e descarregamento dos títulos inseridos nas Bibliotecas Digitais UC Digitalis, UC Pombalina e UC Impactum, pressupõem a aceitação plena e sem reservas dos Termos e Condições de Uso destas Bibliotecas Digitais, disponíveis em https://digitalis.uc.pt/pt-pt/termos.

Conforme exposto nos referidos Termos e Condições de Uso, o descarregamento de títulos de acesso restrito requer uma licença válida de autorização devendo o utilizador aceder ao(s) documento(s) a partir de um endereço de IP da instituição detentora da supramencionada licença.

Ao utilizador é apenas permitido o descarregamento para uso pessoal, pelo que o emprego do(s) título(s) descarregado(s) para outro fim, designadamente comercial, carece de autorização do respetivo autor ou editor da obra.

Na medida em que todas as obras da UC Digitalis se encontram protegidas pelo Código do Direito de Autor e Direitos Conexos e demais legislação aplicável, toda a cópia, parcial ou total, deste documento, nos casos em que é legalmente admitida, deverá conter ou fazer-se acompanhar por este aviso. 


\title{
Saberes e poderes no Mundo Antigo
}

Estudos ibero-latino-americanos

\author{
Volume II - Dos poderes
}

Fábio Cerqueira, Ana Teresa Gonçalves, Edalaura Medeiros \& Delfim Leão (Orgs.)

IMPRENSA DA UNIVERSIDADE DE COIMBRA

UNIVERSIDADE FEDERAL DE PELOTAS

UNIVERSIDADE FEDERAL DE GOIÃS 


\title{
PODER E TERRITÓRIO: O ALTO ALENTEJO ENTRE O IMPÉRIO E A ANTIGUIDADE TARDIA
}

\author{
André Carneiro* \\ Universidade de Évora - Portugal
}

\section{Entre a realidade histórica e o desejo historiográfico}

Nas três últimas décadas o conhecimento existente sobre a paisagem romana ampliou-se dramaticamente. Ao longo dos diversos territórios que pertenceram ao Império temos hoje uma leitura totalmente diferente daquela que a investigação construiu à década de oitenta do século XX. Estes avanços permitem-nos hoje perceber um quadro muito mais complexo, plural e denso nos diversos matizes constituintes de um período que constituiu um momento áureo na densidade e variedade das formas de ocupação humana dos territórios sob a sua égide.

Sem aprofundar muito os diversos feixes de transformação que influíram na perspectiva dos investigadores, pode-se considerar que a ruptura ocorreu por duas ordens maiores de factores.

Uma de âmbito estritamente objectivo, material e vinculada às evidências de terreno. Decorre da progressiva identificação de um conjunto tipológico de unidades de povoamento que foi afinal muito mais variado do que se pensava. 0 avanço da pesquisa (quer por questões relacionadas com as novas agendas de investigação, quer pela emergência da arqueologia preventiva e da minimização de impactos no decurso de obras), dedicando-se gradualmente à detecção de outros pontos de habitação dotados de menor monumentalidade, veio demonstrar algo que uma leitura atenta das fontes já deixava antever: que a paisagem romana apresentava uma espantosa diversidade nas suas unidades de povoamento.

A segunda alteração resulta de um novo paradigma de investigação, que paulatinamente se descentrou dos cânones tradicionais para uma leitura mais

\footnotetext{
* Docente no Departamento de História da Universidade de Évora. Investigador do CHAIAUÉ: Centro de História da Arte e Investigação Artística da Universidade de Évora. O presente estudo está englobado no âmbito da dissertação de Doutoramento em Arqueologia na Universidade de Évora "Povoamento rural no Alto Alentejo em época romana. Vectores estruturantes durante o Império e Antiguidade Tardia", com trabalhos de campo autorizados pelo IGESPAR e que contou com financiamento da Fundação para a Ciência e Tecnologia (FCT). Os trabalhos de SIG foram realizados por Éder Veiga e Ana Carriço sob a orientação do Professor Miguel Marques, da EPRAL de Évora. ampc@uevora.pt
} 


\section{Poder e território: o Alto Alentejo}

descomprometida e menos romanocêntrica. E aqui entramos no domínio subjectivo de uma secular disciplina que foi progressivamente arquitectando uma visão canonicamente assente na valorização do seu próprio domínio de estudo. Ou seja, a análise da paisagem romana foi tranquilamente (porque de forma acrítica e sem discussão) enaltecendo de forma cada vez mais sólida aquela que no fundo resultava ser a mais paradigmática forma de habitação que em si mesmo materializava os conceitos do Imperium e da pax romana: a villa descrita pelos agrónomos clássicos, com a acrescida vantagem de ser este o elemento que pela monumentalidade das suas evidências arquitectónicas ainda hoje mais se distinguia nos campos e mais atraía o esforço de escavação e descrição (proporcionando os achados mais imediatos e espectaculares). Desta forma, os próprios investigadores centraram o seu olhar na villa enquanto grande unidade agro-pecuária e latifundiária (de acordo com a leitura conservadora deixada pelos agrónomos) que de forma hegemónica se estendia pelos campos, criando uma paisagem inteiramente dominada por estas grandes unidades que constituíam a marca mais notável do poder civilizador de Roma.

Esta atitude derivava assim:

a) de uma leitura excessivamente rigorosa e à letra das fontes, esquecendo o seu comprometimento político-cultural fundado em discurso de matriz eminentemente conservadora;

b) de uma postura historiográfica que procurava valorizar a marca de criação imperial da villa como epítome máximo de uma civilização e de um poder político, esquecendo outras formas de habitar o campo e subvalorizando as préexistências do fundo indígena.

c) de uma visão ambivalente da vida rustica no campo assente em um paradoxo: por um lado o interesse pelo estudo da paisagem rural enquanto emblema do espírito latino, mas privilegiando o elemento urbano por excelência dessa paisagem, o edifício da villa e seus urbana ornamenta, esquecendo os próprios espaços mais ligados à vertente rústica destas propriedades ${ }^{1}$.

De modo algo paradoxal, com o advento das posturas processualistas esta leitura radical da investigação tradicional encontrou campo fértil para a sua ampliação e concretização. A aplicação de métodos importados de outras disciplinas, em especial da Geografia Física (como os polígonos de Thiessen ou os modelos de von Thünen) permitiram contar, medir, quantificar e no fundo padronizar a paisagem, repartindo de forma equitativa e a-priorística as diversas unidades, como se o espaço fosse um todo homogéneo, sistémico e standardizado que se estendia até ao infinito.

Em resumo, até tempos recentes a paisagem romana era constituída pelo "padrão-villa" enquanto marca civilizacional de um poder centralizado mas visualmente omnipresente em cada província e em cada lugar. Estas unidades, 
cada uma delas pequenas-Romas em si mesmo, por serem dotadas de um conjunto de elementos constituintes da opulenta vivência clássica, estabeleciam a marca da presença de um momento dourado na história da Humanidade que, pela monumentalidade dos seus vestígios, comprovava ainda hoje a grandeza desse poder. Outras formas de habitar eram insuficientemente conhecidas, desinteressantes para a investigação e, na parca materialidade dos seus restos, um mero testemunho da atávica rudeza das gentes indígenas que assim se mantinham à margem do Império ou incapazes de serem englobadas pelo novo poder civilizador.

Nos últimos anos, porém, a visão alterou-se por completo. Sabemos hoje que a paisagem romana não foi equitativamente povoada nem repartida ad infinitum. Que os impactos da romanidade foram desiguais e diferenciados, funcionando em diversas escalas, consoante as especificidades locais. E que a leitura à letra dos textos clássicos, esquecendo a sempre necessária exegese, criava vícios de interpretação, por não considerar que estes foram uma produção de autor, expressando assim mensagens, ora subliminares ora explícitas, que resultavam ideologicamente comprometidas e que deste modo não correspondiam de todo a situações materialmente observáveis na própria época de produção desses textos ${ }^{2}$.

Nos trabalhos de campo outro factor influía, pois os arqueólogos tendiam a registar as recomendações contidas nos textos clássicos para a implantação dos sítios na paisagem, que permitiam identificar com grande clareza no terreno as condições ideais de enquadramento espacial. Ou seja, no terreno, se os sítios eram encontrados nos critérios gerais definidos nos textos (meia-encosta com boa exposição solar, proximidade de recursos hídricos e solos de aptidão elevada, ampla visibilidade envolvente, proteç̧ão dos ventos de Norte, procurando a amoenitas tão exaltada...) confirmava-se a ideia pré-concebida e dispensava-se o investigador de procurar outras implantações que fugissem à norma. Assim, as regularidades aumentavam.

Finalmente, a diferente percepção de leitura foi também construída a partir de uma visão muito mais desestruturada e complexizante que o mundo pós-moderno hoje tem de si próprio. A ideia de um Império que se impôs às realidades pré-existentes, subsumindo-as no todo global, é difícil de gerir no mundo contemporâneo em que vivemos, um mundo pluricentrado, multivariado e muito mais problematizante. Como resultado, a Romanização é hoje entendida como um complexo fenómeno de interacção cultural, e a paisagem que evoluiu no quadro imperial é assim percebida como tendo sido criada mediante uma poderosa interacção entre o poder de Roma e as estruturas vivenciais indígenas, daí resultando um processo reactivo que foi moldando de forma específica os diversos quadros existentes ${ }^{3}$. 


\section{Poder e território: o Alto Alentejo}

Mas esta percepção da complexidade que hoje temos já deveria ter sido notada há mais tempo. É claramente fruto do mundo em que vivemos, mas a bem dizer, já uma leitura atenta dos textos clássicos deixava antever que a filosofia da construção do Império que Roma criou não se assemelhava a outras experiências na História da Humanidade, como o Império Mongol ou o Napoleónico, por exemplo. Na verdade, a vontade de Roma foi muito particular, e a criação de aí resultante assumiu contornos fortemente originais.

\section{Os diversos olhares de Roma}

O Império romano caracteriza-se pela sua especificidade. Funcionou de modo próprio, com motivações particulares e que se foram alterando em processos muito complexos respondendo a diversas circunstâncias internas e externas. Como nenhum outro, foi fortemente reactivo e adaptável, com cambiantes específicas em função dos interesses metropolitanos mas também das realidades locais.

São os factos históricos que nos permitem construir esta leitura, mas no fundo também os textos da época já expressam de forma clara o pragmatismo latino.

Apiano, historiador do século II d.C., conta-nos que uma das preocupações fundamentais dos imperadores seus contemporâneos se centrou na gestão do adquirido (App. Praef. 7). A filosofia de actuação estratégica deixou de estar centrada na ampliação territorial para passar a olhar para a consolidação dos territórios já absorvidos. Ou seja, Roma voluntariamente travou o seu processo de expansão territorial. Mais surpreendente ainda, mesmo quando alguns embaixadores de reinos exteriores ao Império, os designados "bárbaros", ofereciam os seus haveres e os seus habitantes como súbditos, viam as suas intenções recusadas com o pretexto de não serem de qualquer utilidade para o Império. Roma em nada ganharia com a integração dessas gentes no seu aro.

Este facto recorda-nos o pragmatismo imperial romano. Em certos territórios não interessava prosseguir a expansão territorial. Certas áreas não tinham nada para oferecer, e portanto o olhar de Roma não se dirigia para essa direcção. E este fenómeno não era meramente exterior, ou seja, direccionado para os territórios ainda não conquistados. Na realidade, este desinteresse edificador verificava-se nos âmbitos territoriais do próprio Império, onde o investimento era muito diferenciado. Em termos gerais observamos que em certas áreas existia uma intenção de desenvolvimento e exploração, mas em outros casos os recursos esgotavam-se rapidamente, assistindo-se ao abandono dos mesmos, ou então não havia de todo um esforço promotor concertado que conduzisse a uma sustentação de crescimento. Deste modo, dentro das fronteiras imperiais existiram sempre extensões pouco povoadas ou onde as estruturas 
indígenas preservaram a sua identidade, assistindo-se a uma presença romana escassa ou mesmo nula.

Desta forma, o Império caracterizou-se por ser uma máquina pragmática, organizada e funcional, montada de acordo com motivações precisas, coerentes entre si e fortemente actuantes em função dos meios que se pretendem atingir. Ou seja, direccionadas para elementos estratégicos prioritários, privilegiados em função de outros secundários onde o impacto foi obviamente menor ou mesmo inexistente.

O desafio para a investigação de territórios reside agora na capacidade de diagnosticar em áreas concretas as diversas cambiantes possíveis. Ou seja, em vez de entender a paisagem como um todo homogéneo, perceber como a paisagem romana pode ser encarada enquanto fenómeno complexo, variado e funcionando em diversas escalas, com diferentes impactos e materialidades.

\section{Dados Geográficos}

A área em estudo corresponde genericamente à região designada por Alto Alentejo. Abrange todo o actual distrito de Portalegre e ainda os concelhos de Estremoz, Vila Viçosa e Borba (pertencentes ao actual distrito de Évora), estando geograficamente delimitada por alguns acidentes naturais (bacias hidrográfica do Tejo e Guadiana, serras de S. Mamede e d'Ossa) e pela actual fronteira administrativa com Espanha, situada a Oriente. Caracteriza-se aliás pela proximidade com a actual Extremadura espanhola, sendo este um dado relevante para a época em estudo, visto que nesta área se encontrava a capital administrativa da província da Lusitania, a urbs de Augusta Emerita. Ou seja, [esta] foi uma região que em época imperial era o natural espaço de extensão da metrópole provincial para Ocidente, no sentido do Atlântico.

Este facto ajuda a explicar o forte investimento que a região recebeu em época romana, materializado na construção de três roteiros viários principais que surgem descritos no Itinerário de Antonino, uma tábua de estradas do século III. Estes caminhos, com a designação de XII, XIV e XV, ligavam a capital provincial ao seu porto de mar atlântico, a cidade de Olisipo, actual Lisboa. Orientadas no sentido Este/Oeste, rompem por completo com os tradicionais caminhos da transumância e das migrações pastoris que estão alinhadas em eixos Norte/Sul. Este exemplo mostra como a geografia territorial do Império rasgou os quadrantes tradicionais que organizavam o espaço onde até aí pessoas e bens circulavam, de modo a criar um novo entendimento geo-estratégico de acordo com os interesses da metrópole provincial. Os diversos monumentos e obras de arte que foram edificados ao longo do percurso das três estradas demonstram também a dimensão do investimento aqui realizado e o modo como o Império pretendeu redimensionar esta área territorial. Infelizmente falta-nos ainda uma 


\section{Poder e território: o Alto Alentejo}

outra dimensão de percepção (nomeadamente a proveniente das fontes epigráficas, muito escassas nesta região) para percebermos se esta promoção infra-estrutural se deveu à acção das elites locais ou foi concretizada a partir de determinações superiores.

Um dos elementos mais interessantes, contudo, reside na aparente ausência de um tecido urbano que promovesse e centralizasse as redes viárias e a arquitectura do povoamento rural. Sabendo como o Império romano é a civilização da urbs, e como este modelo enforma toda a dinâmica vivencial, resulta algo paradoxal que no Alto Alentejo tenhamos um aparente vazio de cidades ou de espaços semi-urbanos ${ }^{4}$. Comprovadamente apenas temos a cidade de Ammaia, que no entanto apresenta-se descentrada, porque situada no terço superior da área regional, e distante dos principais itinerários, em especial das já mencionadas três vias de ligação Olisipo/Augusta Emérita. Ou seja, a cidade não se assume como um pólo ordenador de âmbito regional como aconteceu por exemplo com Ebora Liberalitas Iulia ou Pax Iulia, as outras grandes urbs do actual Alentejo, que inclusivamente desempenharam plenamente o seu papel de caput viam e têm uma posição centralizadora face ao seu territorium.

Para o Alto Alentejo apenas temos conhecimento de outro núcleo que poderá ter assumido funções de âmbito urbano. Neste caso com o aliciante suplementar de se ter conseguido uma ligação entre uma menção literária e a realidade arqueológica. Encontra-se em Alter do Chão, onde desde há muito se suspeitava o vínculo da localidade com a mansio Abelterium na via XIV do Itinerário de Antonino. Os recentes projectos de investigação permitiram definitivamente comprovar esta situação, embora seja ainda prematuro perceber o perfil de ocupação e de organização deste local.

O tecido urbano na área em estudo aparece assim algo desestruturado, sendo difícil de perceber se essa seria uma realidade já existente na época ou se é uma impressão provocada pela deficiência da pesquisa que ainda não identificou com segurança alguns locais concretos. Porque na realidade não foi ainda determinada uma correspondência entre as escassas menções conhecidas e as realidades materiais no terreno, funcionando este desfasamento a vários níveis.

Analisemos este ponto a partir dos escassos dados disponíveis. Desta forma, listem-se as menções existentes a eventuais aglomerados secundários na região que ainda não foram localizados.

a) Em primeiro lugar, comecemos pelas possíveis mansiones que estão mencionadas no Itinerário de Antonino:

\begin{tabular}{|l|l|l|}
\hline Via XII & Via XIV & Via XV \\
\hline Ad Atrum Flumen & Matusarum & Fraxinum \\
\hline Dipo & Ad Septem Aras & Montobriga \\
\hline Evandriana & & Ad Septem Aras \\
\hline
\end{tabular}


Apesar dos esforços da investigação ${ }^{5}$ continua a não ser possível localizar no terreno com um mínimo de segurança os locais de implantação destas entidades. Não sabemos a sua exacta localização, a sua relação física com os itinerários nem a sua estrutura de povoamento, ou seja, se seriam povoados de matriz urbana, se estariam alinhados ao longo da via, concentrados, dispersos, aglomerados...

b) Epigraficamente temos apenas uma menção a um vicus:

IOVI / OPTVMO / MAXVMO / VICANI / CAMALO / C [...] IN [?], epígrafe encontrada em Monte do Chocanal (Crato e Mártires, Crato) (IRCP no 609; RP 6/104). Infelizmente não resulta explícita nem a designação do local ${ }^{6}$ nem a menção dos dedicantes, podendo tratar-se de um povoado de filiação indígena, como geralmente se interpretam estes locais (assistindo-se então a uma manifestação de lealdade para com o poder imperial, talvez sincretizando uma divindade indígena à figura tutelar do panteão), ou em alternativa de uma fundação por colonos romanos, eventualmente em contexto de fixação de militares após o seu licenciamento. Seja como for, embora a menção toponímica seja explícita e o local tenha aparentemente sido relocalizado, a sua correspondência com o vicus levanta fundadas dúvidas ${ }^{7}$.

c) Outras menções epigráficas menos explícitas:

DEE SANCTE / BVRRVLOBRI[I] / [G]ENSI Q(uintus?) I(ulius?) EM(eritus?) / $[A($ nimo $)] \bullet L($ ibens $) \cdot V($ otum $) \cdot S($ olvit $)$, encontrada em termo desconhecido do concelho de Elvas ${ }^{8}$. Um dedicante de grande relevância antroponímica, pois apresenta tria nomina, e um topónimo complexo, pois com esta menção se sustentou a hipótese de a actual cidade de Elvas se implantar sobre uma hipotética Burrolobriga. Mas até ao momento a eventual ocupação elvense em época romana ainda não foi esclarecida, pelo que a situação permanece indefinida.

Em resumo) Desta forma se materializa um paradoxo. Temos algumas menções toponímicas cuja correspondência material não se consegue ainda efectuar. De aqui resulta um aparente vazio de estruturas urbanas ou protourbanas, mas afinal sabemos literária e epigraficamente que elas existiriam. A explícita menção de um vicus ou as mansiones viárias noticiadas mostram-nos locais dotados de algum tipo de centralidade, mesmo que de segundo nível e portanto distante do plano urbanístico que uma cidade necessariamente implicava.

Mas o que mesmo assim ressalta da análise é o facto de nenhum destes locais se assumir como uma urbs, como uma cidade dotada de espaços de sociabilidade e com magistraturas locais promotoras de funções urbanas. Mesmo 


\section{Poder e território: o Alto Alentejo}

que não os conheçamos, seriam sempre sítios secundários, de perfil especializado (funções viárias ou sagradas como elementos primaciais, mesmo que possam também ter desempenhado outros papéis) e distantes do que efectivamente entendemos por uma cidade, de acordo com o sentido classicizante da palavra. No Alto Alentejo esse papel parece ter sido reservado exclusivamente para Ammaia, que mesmo assim se apresenta geograficamente descentrada face à região de implantação e ao conjunto de estradas que a percorre.

Em síntese, temos um tecido urbano - ou melhor dizendo, de povoados com potencial centralizador - ainda insuficientemente conhecido, situação que poderemos imputar exclusivamente ao atraso da investigação.

Analisemos agora os dados referentes ao povoamento rural.

\section{Um povoamento multivariado}

Uma das primeiras preocupações do presente projecto de investigação centrou-se na necessidade de, pela primeira vez, reunir toda a informação arqueológica referente aos sítios rurais de época romana no Alto Alentejo. Desde logo se pressentiu o profundo desequilíbrio da investigação e da massa de dados existente, situação que, sendo determinante para a análise explicativa, aqui exigiria um esforço de enquadramento que extravasa o presente estudo.

O conjunto de dados assim reunido em primeira instância foi então cartografado (Figura 1), de modo a se poderem extrair leituras preliminares, necessariamente sujeitas a revisões futuras, mas que de algum modo permitiriam lançar feixes de análise.

Vejamos os dados sob duas perspectivas.

a) Quanto à ocupação do território:

Neste amplo espaço podemos encontrar três tipos de estratégias de povoamento. As manchas de concentração de sítios permitem definir áreas de centralidade, zonas de maior espaçamento inter-sítio e áreas praticamente despovoadas ou onde a ocorrência de locais se deve a factores específicos e concretos.

1. Territórios centrais: aqueles que apresentam maior densidade na distribuição de sítios. Encontramos maiores índices de povoamento ao longo dos itinerários das vias, dos (poucos) núcleos urbanos e dos melhores terrenos agrícolas. Estes pontos de povoamento materializam-se em villae de grande aparato e monumentalidade. Algumas destas unidades são grandes espaços de economia agro-pecuária, muitas são apenas locais de representação de domini pertencentes ou associados às elites urbanas. Nas zonas centrais, com maior número de sítios, o tecido de povoamento parece ter sido reservado quase em 
exclusivo para as villae que apresentam grande visibilidade do ponto de vista da sua expressão material. Por toda esta área encontra-se um padrão de povoamento sobretudo estruturado em grandes villae, especialmente junto ao vale do Guadiana, com uma cultura material exuberante e um conjunto de evidências arquitectónicas e artefactuais que plenamente inserem estes sítios nas correntes materiais e culturais do Império. A distribuição destas villae é obviamente desigual, observando-se concentrações em torno de duas áreas mais localizadas: em torno a Ammaia, nos concelhos de Castelo de Vide e Marvão, por vezes com uma forte densidade, mas onde se evidencia uma cultura material um pouco menos rica e mais vinculada ao fundo indígena; e depois, em torno ao Guadiana e às principais vias de trânsito (XII, XIV, XV), com villae de grande monumentalidade e impacto na paisagem da época, que em vários casos prolongam a sua ocupação para períodos para além do fim do Império.

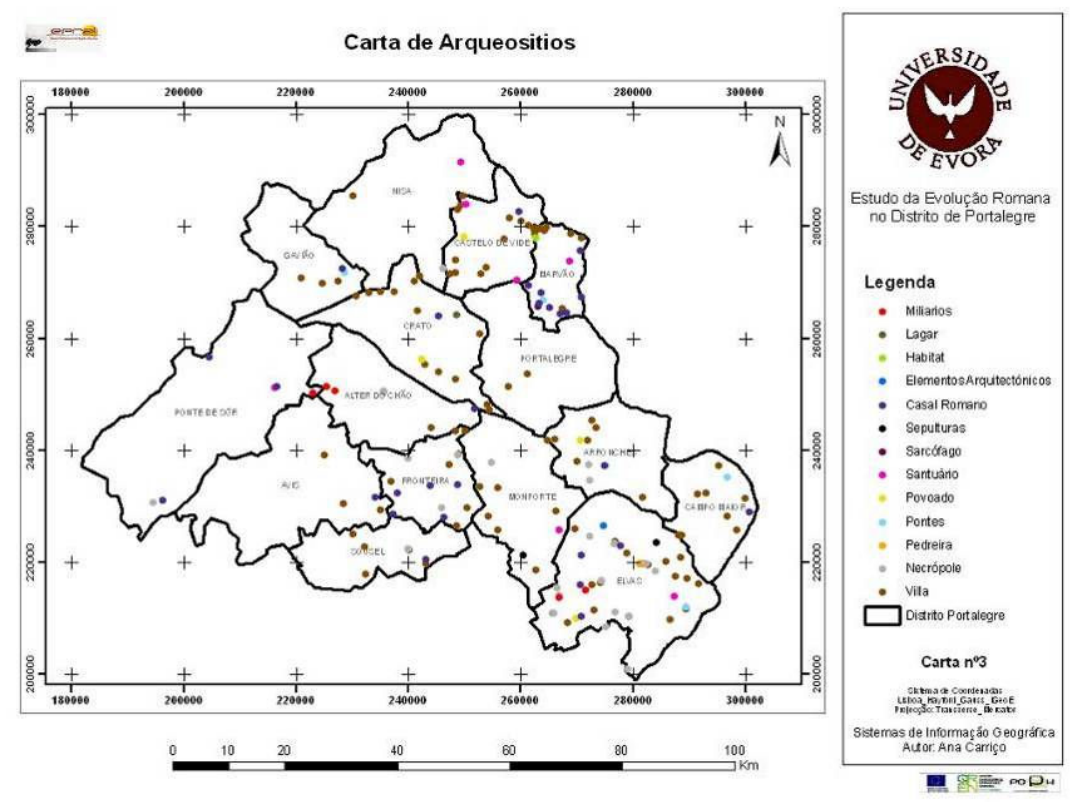

Figura 1.

Geo-referenciação preliminar de 2007 que reuniu a informação então disponível sobre sítios romanos e tardo-antigos na zona em estudo.

2. Territórios periféricos: áreas que apresentam uma concentração média de sítios e onde percebemos também que a cultura material que cada local apresenta é igualmente de índice médio. São pontos ocupando os espaços 


\section{Poder e território: o Alto Alentejo}

deixados livres entre as grandes villae mas beneficiando da proximidade de solos de elevada capacidade agrícola e de linhas de água secundárias com caudal permanente que sustentam pequenas unidades rurais. Nestas áreas predominam os casais de tipo agrícola ou alguns povoados que poderão ter desempenhado funções proto-urbanas, como mansiones e vici ou povoados de tipo aldeia.

3. Territórios ultra-periféricos: em áreas quase desertas e praticamente despovoadas. Por aqui encontra-se uma arquitectura de povoamento desestruturada, sem organização coerente e baseada em sítios autónomos e isolados, próximo de recursos específicos, como de itinerários viários ou de elementos de rentabilidade económica (nomeadamente de mineração ou pedreiras). De um modo geral observa-se que nas paisagens pedologicamente menos aptas, onde hoje dominam os terraços fluviais de cascalheira e de mato arbustivo, a rarefacção de sítios é notória, sendo que ao longo de larguíssimas extensões praticamente não existem pontos de povoamento. São claramente áreas que, por insuficiências de aproveitamento económico, não estimularam a colonização e o incremento romano, ou seja, onde a densidade de presença humana foi praticamente nula ou vestigial.

\section{b) Quanto à organização do povoamento:}

Neste tecido de povoamento podemos definir alguns padrões específicos ${ }^{9}$ :

a) povoamento disperso - em áreas de forte investimento agro-pecuário observa-se que os locais - geralmente as grandes villae - se espalham pela paisagem, repartindo entre si o território de forma espaçada (mesmo que nem sempre homogénea). Os fundi estariam bem delimitados (ainda que para já as fronteiras nos pareçam hoje impossíveis de reconstituir), com uma elevada densidade populacional ocupando espaços repartidos de acordo com as possibilidades dos diversos domini. Ou seja, uma rede de povoamento estruturada e definida de acordo com os interesses específicos do que poderíamos designar como uma elite urbana com posses e proveitos rurais (e de aí podermos observar a proximidade destas villae às urbs ou aos circuitos viários de escoamento preferencial).

b) povoamento agrupado - motivado pela existência de recursos específicos de elevado valor económico ocasionando a presença de uma rede de pontos independentes entre si que se concentram em torno desses valores: a bacia aurífera do Tejo ou o pagus marmorarius de Estremoz poderão ser exemplos. Por aqui encontramos elevadas densidades de sítios atraídos por recursos económicos de rápido retorno. Seria interessante perceber que tipo de pessoas se deslocava para estes locais (mais uma vez falta-nos a dimensão epigráfica), mas será de esperar que a especialização laboral convocasse artífices exteriores, e eventualmente até de pontos distantes do Império $^{10}$. 
Arqueologicamente observamos que a especificidade dos recursos existentes motivou uma concentração de sítios em seu torno, criando um "enxameamento" de pontos de povoamento. Infelizmente, a laboração posterior em alguns destes casos (penso sobretudo nas pedreiras marmóreas) ou a ausência de prospecções intensivas impede-nos de perceber devidamente esta rede de locais e a sua interacção ${ }^{11}$.

c) povoamento alinhado - ao longo de traçados viários encontramos um continuum de lugares que segue esses percursos, motivando um espaçamento sequencial de sítios ao longo da paisagem. Em determinados pontos percebemos que os itinerários funcionaram como um recurso apelativo para a fixação de pessoas, com sítios que se alinham ao longo do traçado, ora imediatamente junto, ora a curta distância. $\mathrm{O}$ abastecimento de bens e produtos e a possibilidade de escoamento de matérias-primas e de circulação de pessoas foram certamente factores preferenciais nesta escolha de localização. No caso das villae temos a facilidade de acesso proporcionada pela estrada, que muito agradava aos seus proprietários $^{12}$.

Outro elemento que funcionou como recurso estratégico terá sido a rede hidrográfica. Resulta revelador observar que alguns cursos de água secundários, de médio porte, foram escolhidos para a implantação de vários sítios ao longo do seu traçado. Tal não se verifica nas linhas de água principais - o Tejo, certamente devido ao alcantilado das margens, e o Guadiana, talvez devido à irregularidade e impetuosidade do seu caudal - mas em seus afluentes mais domesticáveis, o que se prende também com a construção de barragens e açudes necessários à implementação de uma prática agrícola de regadio. Como resultado, alguns pequenos rios funcionaram como factores preferenciais de povoamento, pois ao longo dos seus cursos dispõem-se vários sítios arqueológicos.

Estamos portanto distantes de uma paisagem standardizada e homogénea. Quer nos padrões de distribuição, quer na estrutura da rede de povoamento, observamos importantes distorções nesta área regional, por vezes ocorrendo de forma brusca entre espaços vizinhos. Zonas de denso povoamento contrastam com outras onde parece ter existido uma baixíssima densidade populacional; áreas de propriedades repartidas contrastam com outras onde notamos a polarização ou o alinhamento sequencial de sítios. E não estamos ainda em momento de podermos definir o perfil de ocupação de cada local, pois seria interessante introduzir este nível de leitura. Ou seja, seria muito revelador perceber qual a funcionalidade de muitos destes sítios, se mais dedicados à vocação agro-pecuária, ou a funções comerciais, ou sagradas, ou vinculados à mineração... Tal só poderá ser conseguido com o intensificar de escavações que nos permitam perceber o que cada um destes locais efectivamente foi. Da mesma forma seria necessário elevar os índices epigráficos, ainda muito escassos, quer 


\section{Poder e território: o Alto Alentejo}

nas inscrições pétreas, quer nos grafitos sobre cerâmica, sendo estes importantes para avaliar o nível de literacia e de envolvimento cultural destas comunidades. Assim se poderia progredir na leitura, criando patamares em que mais variáveis analíticas poderiam ser introduzidas. Mas infelizmente a irregularidade da investigação arqueológica no Alto Alentejo ainda não nos permite funcionar nessa órbita.

Seja como for, o que parece resultar evidente desta primeira reunião de dados assenta na ideia que as redes de povoamento romano no Alto Alentejo apresentam uma organização que reflecte o investimento Imperial e as realidades económicas que o meio naturalmente oferecia. Quer isto dizer que as redes de povoamento são multivariadas, como já foi afirmado. Agem de acordo com interesses específicos, em perspectivas profundamente pragmáticas. O poder central terá estabelecido directivas que são concretizadas no terreno de acordo com os interesses estratégicos do Império, não hesitando em criar uma nova geografia de raiz, obliterando o pré-existente. Proporcionadas as condições infraestruturais, compete aos privados organizar o tecido de povoamento.

Certos recursos económicos foram prioritários e motivaram a atracção no estabelecimento. A mineração ou as pedreiras são exemplos já citados e arqueologicamente mais óbvios ${ }^{13}$. Quanto aos recursos agro-pecuários e à exploração do meio, seguramente foram deixadas a privados, que construíram grandes estruturas fundiárias para a sua laboração. Em zonas de solos adequados e de uma rede hidrográfica densa observamos que as villae foram o elemento de povoamento preferencial ${ }^{14}$. Em áreas menos aptas, ou mais distantes das vias, os casais ou os pequenos povoados de tipo aldeia poderão ter sido a base de instalação para comunidades menos sólidas do ponto de vista da sustentação económica, operando em condições subsistenciais mais precárias.

O papel do Estado central baseou-se na criação de uma rede viária que pusesse em contacto os distintos mercados. Estes corredores de circulação constituíram-se posteriormente como os elementos fundadores de uma rede de povoamento que os tomou como eixo prioritário. Ou seja, no Alto Alentejo vemos uma dupla dinâmica: por um lado a acção estatal, criando infra-estruturas de funcionamento; por outro a iniciativa privada, a cargo de potentiores de elevada capacidade económica que operavam distribuindo entre si os melhores recursos de acordo com as possibilidades de investimento de cada um. O que viria a emergir seria uma paisagem fortemente hierarquizada, dinâmica, inter-actuante e onde se torna evidente uma constante adequação entre os recursos disponíveis e a infra-estruturação agora construída.

Como já foi lembrado, faltam-nos muitos dados essenciais para a análise. Um desses vectores reside, por exemplo, na percepção do papel que as comunidades indígenas tiveram. Seria interessante perceber se estes territórios 
centrais já o seriam em momento pré-romano, articulando as redes de povoamento da Idade do Ferro. Tal para já não resulta claro, mas cada vez mais parece óbvio que o impacto romano transformou completamente a paisagem, criando uma nova mundividência. Em especial as três vias terão desempenhando um papel fundamental, rasgando os horizontes em que até então funcionava esta região e criando um nível de inserção nas dinâmicas do Império que a capital provincial sabiamente saberá articular e gerir. A paisagem que neste momento se implementa é profundamente romana, pragmática, estruturada e organizada de modo a maximizar as potencialidades económicas deste território.

O outro dado essencial para análise poderá eventualmente ser ultrapassado com futuras descobertas epigráficas e através de escavações sistemáticas e metódicas em sítios arqueológicos. Destina-se a procurar perceber o papel dos promotores privados neste processo. Quem eram os terra tenentes, que motivações tinham para a gestão do território, como organizaram entre si os diversos latifúndios e repartiram propriedades dividindo o espaço ${ }^{15}$. Como eram os espaços arquitectónicos em que residiam e como investiram na criação ou beneficiação de estruturas de transformação agrícola e produção industrial. Em que nichos económicos apostaram preferencialmente e como congregaram as comunidades que habitavam localmente ${ }^{16}$. Em resumo, torna-se fundamental conhecer o papel das elites privadas e o modo como as redes clientelares e as relações de poder se foram estruturando e implementando, articulando-se com as formas de ocupação do território.

Finalmente, o dado essencial que nos falta reside na densificação do espaço. Faltam-nos nomes, locais, materiais arqueológicos, contextos, estratigrafias, plantas de sítios, etc. A convergência de indicadores permitir-nos-á lançar outros feixes de análise, mas de momento a presença romana no Alto Alentejo apresenta-se-nos ainda demasiado indefinida, demasiado vazia para podermos proceder a uma análise sustentada.

\section{Durante a Antiguidade Tardia: evoluções finais}

Embora não existam sequências estratigráficas que permitam ler os ritmos de evolução, parece existir uma grande estabilidade nos principais sítios rurais, nomeadamente nas villae. Até ao século $\mathrm{V}$ não parece existir uma radical transformação dessa rede de povoamento.

Em leitura geral, as grandes villae permanecem ocupadas ${ }^{17}$. Os nexos de continuidade encontram-se nos territórios que em época imperial pareciam mais "romanizados", e por isso conservam a sua identidade e vitalidade. Ou seja, os sítios de maior dinâmica durante o século III e IV parecem conservar essa energia durante as décadas seguintes, mantendo-se em actividade durante algum tempo $^{18}$. 


\section{Poder e território: o Alto Alentejo}

As villae menos estruturadas, de "segunda ordem", parecem ter um fim mais prematuro, eventualmente sendo englobadas em fundi de maiores dimensões devido à concentração das propriedades fundiárias e entretanto abandonadas ou reconvertidas funcionalmente ${ }^{19}$.

Olhemos agora para as dinâmicas gerais, respeitantes às redes de povoamento. Aqui observamos o mesmo problema resultante da ausência de dados estratigráficos e de cronologias gerais.

Os primeiros sítios a ser abandonados serão os locais ultra-periféricos que oferecem menores garantias para a subsistência económica dos seus ocupantes. Esta retracção manifesta-se deixando vazios nas áreas onde a densidade populacional já em época imperial era mais débil e que agora aparecem completamente vazias. As zonas de menor aptidão agrícola ou onde os recursos eram escassos são agora deixadas vazias, mostrando como o Império foi também, do ponto de vista demográfico, um momento de dinâmica excepcional na presença antrópica na região. Quando surgem os indicadores de crise, ou de instabilidade, são estes os primeiros locais a serem abandonados no momento de retracção das redes de povoamento ${ }^{20}$. Deste modo, os dados referentes ao século $\checkmark$ mostram-nos já o que parece ser o vazio de presença humana em largas margens destes territórios.

Muitos dos locais periféricos são também progressivamente abandonados, resistindo aqueles que se encontram mais próximo de recursos estratégicos (vias ou solos de elevada aptidão agrícola). Neste refluxo, muitos dos sítios em territórios periféricos deslocam-se para cotas mais elevadas ou para locais mais "escondidos" na paisagem, assistindo-se progressivamente à substituição de um modelo de povoamento aberto e voltado para a circulação de pessoas e bens por outro mais fechado, desestruturado e com os sítios isolados entre si. Em especial nas zonas montanhosas da Serra de S. Mamede, com relevos mais alcantilados e propícios à insularização dos sítios, parece ser este o modelo predominante, com povoados ocupando cotas mais elevadas ou zonas de mais difícil acesso. Também junto a alguns cursos de água parecem surgir povoados de tipo "lacustre", à semelhança de outras regiões ${ }^{21}$.

Como foi referido, parece ser nos territórios centrais e nos sítios mais romanizados que os nexos de continuidade serão maiores ${ }^{22}$. Mas seria fundamental perceber os modos de consolidação deste processo. É provável que com o colapso da administração Imperial a primazia no terreno passasse para as mãos dos poderosos domini locais, que foram congregando à sua volta os valores económicos, políticos e sociais. Todavia, não sabemos como se desenrolou este processo, tão-pouco sabemos como se processava o exercício do poder em época Imperial nesta área regional - se a cargo das magistraturas locais, se de poderes provinciais, se já com algum papel relevante por parte de privados. 
Mesmo sem determos muitas chaves de percepção deste processo, o que a visão cartográfica preliminar nos permite perceber é o modo como são os sítios mais plenamente inseridos nos circuitos do Império (e como tal, do poder e das redes de influência) aqueles que melhor resistem ao avanço do tempo. Ao longo do século $\mathrm{V}$ e mesmo do $\mathrm{VI}$ parecem ser as villae monumentais os lugares que chamam a si a centralização das redes de sociabilidade. Esta progressiva centralidade parece fazer-se por duas vias.

Por um lado pelo reforço e ampliação das estruturas de transformação agrícola (como os lagares e adegas de Torre de Palma em Monforte que são progressivamente beneficiados), que parecem ganhar funções acrescidas, ou seja, deixando de servir unicamente para a laboração da propriedade em que estão inseridas para passarem a receber produções de outros sítios. Aqui poderemos entrever um processo de concentração fundiária que seria conveniente conhecer com maior profundidade ${ }^{23}$.

O outro vector fundamental para a transformação das redes de dependência será a consolidação do Cristianismo. Não sendo este o momento ideal para desenvolver o tema, parece lógico supor que a construção de basílicas rurais nesta região (seguramente Torre de Palma, possivelmente São Pedro dos Pastores em Campo Maior, São Pedro em Sousel, Silveirona em Estremoz, São Pedro de Almuro em Monforte....) implica uma ruralização das redes de dependência social, com o acréscimo de poder e influência de domini que teriam estes locais de culto integrados nos seus fundi ${ }^{24}$.

Em todo este processo podemos ler duas tendências nos sistemas de povoamento: o refluxo dos modelos de povoamento imperiais, agora quase confinados aos lugares centrais devido ao abandono dos territórios periféricos e ao quase-abandono dos lugares periféricos, o que implica que durante o século $\mathrm{V}$ e parte do VI os lugares habitados são aqueles que em momento anterior já eram os melhor consolidados; e, embora seja ainda muito cedo para o afirmar com segurança, o que parece ser a progressiva transferência da esfera do poder que passa dos agentes públicos para as mãos dos promotores privados, mediante o duplo expediente da concentração e ampliação dos meios de produção e da construção e da manutenção dos locais de culto público, agora nas suas propriedades.

\section{Leitura geral}

A visão que hoje temos da paisagem romana continua a ser condicionada por alguns pré-conceitos (no sentido etimológico do termo) construídos por sucessivas gerações historiográficas. O modo como o Império construiu a paisagem humanizada foi ditado por interesses específicos, por um fortíssimo pragmatismo baseado em interesses económicos e vivenciais concretos. Entender 


\section{Poder e território: o Alto Alentejo}

o território como um todo homogéneo baseado em sucessões de fundi articulados em torno de grandes villae é efectivamente esquecer o modo como a sociedade itálica encarou a expansão territorial e a edificação de um Império.

No Alto Alentejo vemos o modo como a rede de povoamento se estendeu de acordo com uma lógica pragmática. Espaços fortemente monumentalizados e plenamente inseridos nos circuitos imperiais; zonas mistas, com menor densidade populacional e a manutenção de uma identidade específica; e áreas extensas onde encontramos poucas gentes, com assentamentos ditados por motivações muito particulares. Um território diverso, heterogéneo e onde o papel dos centros urbanos permanece para já indefinido em larga medida.

O povoamento da Antiguidade Tardia conserva elementos de continuidade nos territórios onde o impacto do Império foi maior. Os espaços periféricos e ultra-periféricos são lentamente esvaziados, mostrando como a época romana foi também um período de apogeu demográfico. Se o Império romano significou um momento áureo na densidade de ocupação do território (o que, note-se, é diferente de densidade populacional, significando antes a existência de múltiplos sítios vocacionados para a exploração de recursos específicos que são abandonados quando estes se esgotam), será óbvio que para momentos de retracção sejam as áreas marginais as primeiras a serem abandonadas.

Nos territórios centrais, contudo, a impressão que fica é a de uma grande estabilidade e resistência à evolução do tempo preservando as marcas imperiais por longo tempo. Regressando a Apiano vemos que resistiram melhor os terrenos da marca romana, enquanto os espaços que não eram úteis a Roma são os que mais rapidamente se despovoam.

\section{Agradecimentos}

Presto o meu agradecimento, pelos trabalhos de SIG, a Éder Veiga, Ana Carriço e Professor Miguel Marques. 
André Carneiro

\section{Bibliografia}

a) Siglas:

IRCP = Encarnação, José d'. Inscrições Romanas do Conventus Pacensis. Coimbra: IAFLUC, 1984.

RP = Alarcão, Jorge de. Roman Portugal. London: Warminster \& Phillips, 1988.

\section{b) Mencionada no texto}

ALARCÃO, J. de. As vias romanas de Olisipo a Augusta Emerita. Conímbriga, vol. XLV, Coimbra, p.211-251, 2006.

BROGIOLO, G.P.; CHAVARRIA ARNAU, A. El final de las villae y las transformaciones del territorio rural en Occidente (siglos V-VIII). In: FERNÁNDEZ OCHOA, F.; GARCÍAENTERO; GIL SENDINO (eds). Las villae tardorromanas en el occidente del Imperio. Arquitectura y función. IV Coloquio Internacional de Arqueología en Gijón, Gijón, Ediciones Trea, 2008, p.193-213.

CARNEIRO, André. A cartografia dos cultos religiosos no Alto Alentejo em época romana: uma leitura de conjunto. Hispania Antiqva, no 33-34, 2009-2010, p.237-272.

CARNEIRO, André. Em pars incerta. Estruturas e dependências agrícolas nas villae da Lusitânia. Conímbriga, Coimbra, IAFLUC, vol. XLIX, 2010, p. 225-250.

CHAVARRIA ARNAU, A. El final de las villae en Hispania (siglos IV-VIII). Turnhout (Bibliothéque de l'Antiquité Tardive 7), Brepols Publishers, 2007.

CUNHA, M.W. As necrópoles de Silveirona (Santo Estevão, Estremoz). Do mundo funerário romano à Antiguidade Tardia. (O Arqueólogo português. Supl. 4), Lisboa: MNA, 2008.

DYSON, S. II. The romanization of the countryside. Introduction. In: BARKER, G.; LLOYD, J. (eds). Roman landscapes: archaeological survey in the mediterranean region. London: British School at Rome (Archaeological Monographs of the British School at Rome 2), 1991, p.27-28.

GREENE, K. The Archaeology of the Roman Economy. London: Batsford, 1986.

LEWIT, T. 'Vanishing villas': what happened to elite rural habitation in the West in the 5th6th c.? Journal of Roman Archaeology, vol. 16, p.260 -274, 2003.

MANTAS, V. A sociedade luso-romana do município de Ammaia. In: GORGES, J. G.; NOGALES BASARRATE, T. (coord.). Sociedad y cultura en Lusitania romana, IVa mesa redonda internacional, Mérida, Junta de Extremadura, 2000, p.391-420.

MARZANO, A. Roman villas in central Italy. A social and economic history. Leiden-Boston : Brill, 2007.

RAYNAUD, C. Les campagnes en Gaul du Sud-Est dans l'Antiquité Tardive et le Haut Moyen Âge. Zephyrus 53-54, Salamanca, p.473-507, 2000-2001.

SAA, M. de. As grandes vias da Lusitânia: O itinerário de Antonino Pio. 6 volumes, Lisboa: Ed. Autor, 1956-1967.

TERRENATO, N. The Auditorium site in Rome and the origins of the villa. Journal of Roman Archaeology, Volume 14, p.5-32, 2001.

VAN OSSEL, P.; OUZOULIAS, P. Rural settlement economy in Northern Gaul in the Late Empire: an overview and assessment. Journal of Roman Archaeology, volume 13, p.133-160, 2000.

VASCONCELOS, J.L. de. Religiões da Lusitânia. Lisboa, 3 vols. [Vol. II: 1905], 1905-1913. 


\section{Poder e território: o Alto Alentejo}

VIGIL-ESCALERA GUIRADO, A. El modelo de poblamiento rural en la Meseta y algunas cuestiones de visibilidad arqueológica. In: LOPEZ QUIROGA, MARTINEZ TEJERA, MORÍN, (eds) Gallia e Hispania en el contexto de la presencia "germánica" (s. V-VII). Balance y perspectivas. Actas de la mesa redonda, Madrid, 19-20 Deciembre 2005 (BAR International Series 1534), Oxford, 2006, p.89-108

WICKHAM, C. Una historia nueva de Alta Edad Media. Europa y el mundo mediterráneo, 400-800. Barcelona: Crítica, 2009.

\section{Notas}

${ }^{1}$ Sobre o tema realizei uma tentativa de síntese em Carneiro, 2012.

${ }^{2}$ Nicola Terrenato (2001, p.124-25) realçou recentemente que até ao momento não foi encontrado qualquer exemplo de villa que corresponda ao austero modelo catoniano onde não existe qualquer concessão ao conforto. Pelo contrário, em todas as estruturas até hoje consideradas a componente de otium e de voluptas está bem exaltada em termos de planimetria e de aparato decorativo, correspondendo ao modelo helenístico do paradeysos.

3 Em perspectiva mais abrangente, a valorização das formas de povoamento especificamente romanas insere-se no âmbito de fronteiras de estudo onde os investigadores enaltecem excessivamente os seus próprios objectos de investigação. Ou seja, um estudioso do Império romano tende implicitamente a valorizar o seu domínio de estudo face a outras formulações específicas existentes dentro do universo de estudo mas que não foram criadas pela marca itálica (que portanto são de substrato indígena). É o processo que Chris Wickham (2009, p.37) designa de "solipsismo cultural" que no fundo ocorre em qualquer domínio de trabalho, mas que em entidades culturais fortes tende a subsumir as realidades próximas. O conceito fica materializado na provocadora afirmação de Stephen Dyson (1991, p.27): "It is probably an overstatement to claim that many Romanists are really closet colonialists at heart [...]. Essential to this type of thinking is the notion that in the western part of the Roman empire, the creation of the new order required the extermination of the natives and their replacement by a largely Roman population. For political and ritual reasons, Roman generals emphasised and even exaggerated the casualties they had inflicted on the groups that they had conquered. Historians both ancient and modern have stressed the number of slaves that were taken from areas that the Romans conquered. The picture that results from these two processes is one in which the native population is either eliminated or reduced to a marginal existence".

${ }^{4}$ A menos que esta rarefacção urbana denuncie uma grande vitalidade do povoamento rural: "[...] the density of rural settlements is so great that the significance of towns (or even villages) is proportionally reduced. Local markets, and craft activities independent of towns, must have been of considerable importance, and must be taken into account in an analysis of the economy in general. [...]" (GREENE, 1986, p.109).

${ }^{5}$ Ver as múltiplas tentativas feitas por Mário Saa (1956-1967) ao longo dos vários volumes da sua controversa obra. Para uma análise mais recente e fundamentada, Alarcão (2006).

${ }^{6}$ Os vicani camalo[cani?, censis?]. 
${ }^{7}$ No inventário nacional de sítios arqueológicos a respectiva ficha menciona uma área de cerca de $1200 \mathrm{~m}^{2}$, que obviamente parece pouco coincidente com a importância de um vicus. Quanto a um muro construído com grandes blocos de granito, aqui poderíamos ter um elemento de maior vulto, eventual podium de uma estrutura. De acordo com a Base de Dados Endovélico, http://www.igespar.pt/, consultada em Abril de 2010. Ver Carneiro, 2009-2010.

${ }^{8}$ Leite de Vasconcelos (1905, p.174) indica-nos assim a menção da peça: "estive no Museu de Elvas, onde vi uma lapide apparecida nessa cidade [...]", mas não apresenta pormenores quanto à descoberta, presumindo-se que tenha surgido no núcleo urbano. Ver também IRCP no 566.

${ }^{9}$ Seguindo as terminologias de Vigil-Escalera Guirado (2006, p.90) e partilhando das observações do autor: "En lengua inglesa existen una serie de términos específicos para referirse a determinados tipos de asentamientos rurales en función de su tamaño (stead/farmstead, hamlet, village). Granjas, aldeas y pueblos no son un exacto equivalente en español [...]."

${ }^{10}$ A percentagem de clunienses já notada por Vasco Mantas (2000) na cidade de Ammaia pode ser um sintoma desta situação.

${ }^{11}$ Para além das situações motivadas por recursos específicos, é de notar que o território teria uma relevante presença de povoados agrupados, mesmo em zona de grande densidade de villae. Em todos os pontos do Império é muito rara a presença de sítios com vincado modelo esclavagista (contradizendo a proposta columeliana), sendo por isso de assumir que o recurso a mão-de-obra livre que habitaria nas imediações seria mais frequente que o geralmente considerado. Veja-se, por exemplo, a perspectiva de Chris Wickham (2009, p.401): “[...] en todas las épocas existió una materia prima de fácil disponibilidad con la que organizar unas relaciones de producción de tipo esclavista. [...] Sin embargo, los esclavos constituyen un riesgo. Cuanto más numerosos sean, más peligroso y caro resulta controlarlos. Además, es preciso mantenerlos, tanto en las temporadas de bonanza como en las de penuria, en los años buenos y en los malos, mientras que los trabajadores asalariados podían ser despedidos y los tenentes confiados al producto de sus propias parcelas. Para poder cubrir estos riesgos, la utilización de esclavos presupone la existencia de unos elevados niveles de beneficio por la venta de los productos." Ver também a opinião de Chavarría Arnau (2007, p.55).

${ }^{12}$ Alguns destes diverticuli privados de acesso às propriedades ainda hoje se encontram preservados ou servindo como caminhos vicinais. Sobre o facto de as propriedades próximas de traçados viários serem as mais pretendidas por compradores, ver o exemplo fornecido por Plínio o Jovem quando o seu amigo Tranquillus pretende adquirir uma casa de campo com fáceis acessos (Plin. Ep. 5.1.24).

${ }^{13}$ Para outras produções mais difíceis de rastrear na evidência arqueológica ver Carneiro, no prelo.

${ }^{14} \mathrm{O}$ sistema repete-se para outras regiões do Império. Ver, por exemplo, o estudo de Marzano (2007, p.177) para o centro de Itália: "The farther one travels from towns, the more the size of villas diminishes; their production must consequently have been intended mostly for self-consumption, since smaller fundi imply a smaller or nonexistent surplus.. 
${ }^{15}$ Como é óbvio, à medida que avança a dissolução do Império o papel das elites rurais vai aumentando, pelo que seria de toda a conveniência poder caracterizá-los de forma mais apurada, situação dramaticamente dificultada com a redução dos índices epigráficos e dos conjuntos funerários. Como afirma Chris Wickham (2009, p.698), "una jerarquía organizada en torno a los centros rústicos es obviamente una jerarquía que concede prioridad a los terratenientes", pelo que seria fundamental poder proceder à sua análise no contexto da evolução das economias microrregionais.

${ }^{16}$ Por exemplo, Plinio deixou-nos referências sobre um conjunto de grandes investidores que se dedicaram às produções vitivinícolas (Plin. NH 48-49). Todos eram libertos que decidiram reinvestir na terra os proveitos conquistados no artesanato e comércio, formando um novo grupo de promotores agrícolas.

${ }^{17}$ Mesmo que possam existir ligeiras descontinuidades do ponto de vista topográfico, ou seja, pequenas cambiantes, com a existência de permanências não sequenciais. Tal parece ser o caso de Silveirona (Estremoz), conforme estudado por Mélanie Wolfram Cunha (2008) ou de Terrugem (Elvas), com conjunto de referências em RP 6/217. Em ambos os casos as estruturas romanas são depredadas e reutilizadas em espaços paleocristãos, cuja implantação não se faz sobre estas, mas em espaços anexos. Arqueologicamente podemos falar de sítios de estratigrafia horizontal em vez de sítios de estratigrafia vertical como é mais habitual.

${ }^{18}$ Seria interessante perceber se, além de continuarem habitados, manteriam os mesmos ambientes, ou se entrariam em mutação que os desprendesse dos cânones estéticos clássicos, agora "socialmente irrelevantes" como propõe Tamara Lewit (2003, p.268).

${ }^{19}$ Ver o caso da Itália central mencionado por Annalisa Marzano (2007, p.211, e reflexões em p.212-213) com documentação literária. Para a Hispânia ver os vários trabalhos de Chavarría Arnau (Cf. 2007, p.7-138).

${ }^{20}$ Não é original chegar a esta conclusão, pois tal tem sido verificado em vários pontos do Império. Talvez a primeira constatação tenha sido feita por Van Ossel e Ouzoulias (2000, p.9-140)

${ }^{21}$ No Alto Alentejo tal acontece pelo menos nas actuais albufeiras de Póvoa e Meadas e de Caia. O fenómeno foi detectado na Gália: "Au contraire, des zones vides ou peu fréquentées jusqu'alors, en particulier basses vallées, deltas et régions lagunaires, font l'objet d'une intense colonisation aux IVe et Ve siècles." (RAYNAUD, 2000-2001, p.492). Como refere o autor, talvez tal se deva ao incremento de práticas de pastorícia e de agricultura em terraços fluviais modelados pelo Homem, como aliás no Alto Alentejo também ainda hoje se nota, dada a presença de parcelamentos que deverão ter correspondido a áreas de cultivo entre o povoado e a linha de água. Ver também Brogiolo e Chavarría Arnau (2008, p.204). Tirando estes casos específicos, poucos pontos de povoamento parecem ser criados neste período, situação que de resto já foi notada para outras regiões (VAN OSSEL, OUZOULIAS, 2000, p.137).

${ }^{22}$ Situação que parece repetir o que sucede em outras províncias: “En las tierras más fructíferas, son muy pocas las zonas en que se observan casos relevantes de abandono del campo, según empiezan a mostrarnos los análisis polínicos. Lo mismo implica el hecho habitual de que los microtopónimos romanos de grandes zonas de Francia o Italia hayan llegado hasta nosotros, así como las pautas romanas de división de los campos de labor en 280 
centurias o espacios cuadrangulares que pueden apreciarse en Italia o en Túnez y las particiones premedievales de parcelas - de regularidad sólo levemente inferior - que son características de Inglaterra. Todos estos hechos son otros tantos argumentos que contradicen cualquier tipo de teoría que postule la existencia de grandes catástrofes en el sistema agrario" (WICKHAM, 2009, p.779).

${ }^{23}$ No Alto Alentejo terão ocorrido importantes processos de concentração fundiária, com o abandono ou condenação de sítios em favor de outros. Apesar dos escassíssimos dados estratigráficos e artefactuais, parece ser plausível pensar na existência de duas fases de encerramento na ocupação de sítios. Para uma visão mais geral desta evolução ver Chavarría Arnau (2007, cap.IX).

${ }^{24}$ Entre a bibliografia disponível sobre o processo ver as considerações de Alexandra Chavarría Arnau (2007, cap.X). 